\title{
Hospital-physician relations: the relative importance of economic, relational and professional attributes to organizational attractiveness
}

\author{
Jeroen Trybou ${ }^{1 *}$, Paul Gemmel2 , Yves Van Vaerenbergh $^{3}$ and Lieven Annemans ${ }^{1,4}$
}

\begin{abstract}
Background: Belgian hospitals face a growing shortage of physicians and increasingly competitive market conditions. In this challenging environment hospitals are struggling to build effective hospital-physician relationships which are considered to be a critical determinant of organizational success.

Methods: Employed physicians of a University hospital were surveyed. Organizational attributes were identified through the literature and two focus groups. Variables were measured using validated questionnaires. Descriptive analyses and linear regression were used to test the model and relative importance analyses were performed.

Results: The selected attributes predict hospital attractiveness significantly (79.3\%). The relative importance analysis revealed that hospital attractiveness is most strongly predicted by professional attributes (35.3\%) and relational attributes (29.7\%). In particular, professional development opportunities (18.8\%), hospital prestige (16.5\%), organizational support (17.2\%) and leader support (9.3\%) were found to be most important. Besides these non-economic aspects, the employed physicians indicated pay and financial benefits (7.4\%) as a significant predictor of hospital attractiveness. Work-life balance and job security were not significantly related to hospital attractiveness.

Conclusions: This study shows that initiatives aimed at strengthening physicians' positive perceptions of professional and relational aspects of practicing medicine in hospitals, while assuring satisfactory financial conditions, may offer useful avenues for increasing the level of perceived hospital attractiveness. Overall, hospitals are advised to use a differentiated approach to increase their attractiveness to physicians.
\end{abstract}

\section{Background}

Worldwide, hospitals face challenging times. Physicians play a central important role in shaping the increasingly competitive environment in which hospitals operate. First, in response to financial pressures, hospitals attempt to realize economies of scale and adopt strategies dedicated to increase the flow of patients into the hospital. The primary strategy has been described as a 'medical arms race' in which hospitals compete by increasing their share of physicians who admit patients to the hospital in order to maximize hospital occupancy rates [1]. In this sense hospital competition for patients and market share occurs on the physician level. Second, while hospitals traditionally

\footnotetext{
* Correspondence: jeroen.trybou@ugent.be

'Department of Public Health, Ghent University, De Pintelaan 185, Gent B-9000, Belgium

Full list of author information is available at the end of the article
}

faced only competition from other hospitals, today's health care delivery is characterized by the proliferation of physician-owned outpatient facilities that potentially compete with full-service hospitals [2]. Third, in many countries hospitals are confronted with a chronic physician shortage and an exponential increase in the demand of care $[3,4]$. Since the growth in demand is likely to intensify because of ongoing progress in medical science, emerging new technologies and ageing populations [5], physician retention is a hospital management priority.

In this challenging environment hospitals have been struggling to build effective hospital-physician relationships [6] which have been pointed out as a critical determinant of organizational success [7]. Considering the confluence of these forces, it is not surprising that Hospital-Physician 
Relationships (HPRs) are an important area of academic research and a key concern of hospital managers and health policy makers. Moreover, given the central important role of physicians in hospital care delivery, it has been shown that HPRs have an impact on quality of provided care [8], hospitals' financial performance [9] and cost-effectiveness of health care delivery [10].

Previous research has offered a number of important insights into the management of HPRs ranging from a financial view with a focus on alignment of incentives to a non-economic focus which aims at optimizing the working environment of physicians [11]. In this paper we build further on this endeavor by investigating the relative importance of several organizational attributes (economic, relational and professional) to physicians. This study was guided by psychological contract theory and the concept of an attractive organizational image to investigate the relative importance of hospital attributes to physicians and increase insight into the complex hospital-physician relationship. Surprisingly, no previous studies have explored hospital image beliefs of physicians. Yet, such an examination is of practical and theoretical importance.

First, although the concept of an attractive organizational image has received a lot of theoretical attention, relatively few empirical studies have examined this issue. Moreover the available studies have focused primarily on potential applicants' impressions of organizations as employers in the recruitment process. While these studies have increased insight on the factors driving organizational attractiveness for job seekers [12] we do not yet know what determines attractiveness for those people already working at the organization. Furthermore, despite its importance the content or basis of these impressions has remained virtually unexplored [13]. From a hospital perspective, it should be clear how the image of a hospital determines the attractiveness for physicians to work for that particular organization. In light of the physician shortage [4], the physician fled to ambulatory facilities [2] and increased competition between general hospitals [14], the concept of hospital attractiveness is of major importance.

Second, from an academic point of view it might be interesting to know which organizational attributes (economic, relational and professional) are important to professional employees. Moreover, empirical evidence demonstrates that employee-organization dynamics are more complex than has been acknowledged previously [15] and that professional employees like physicians do not adhere to reciprocity principles in a straightforward fashion as originally conceived to be [16]. Although previous research has stressed the importance of economic [17], relational [18] and professional [19] aspects, no previous studies have explored these dimensions of the HPR simultaneously and little is known about their relative importance. Figure 1 provides an overview of the conceptual framework guiding this study.

\section{Theoretical background and hypotheses}

In recent years the concept of an attractive organizational image has received increasing attention within the field of human resource management. In its essence, the organizational image can be described as a mixture of attributes, tangible or intangible, symbolized in a trademark, which can be managed to create value and influence [20]. Since different organizational attributes contribute to this image we argue that this concept is closely related to the concept of the psychological contract. More precisely, the psychological contract consists of individual's beliefs regarding terms and conditions of the exchange between the individual and his or her organization [21]. It refers to the way the working relationship is interpreted, understood and enacted. Psychological contract theory is considered to be one of the most influential theories to understand organizational behavior. There has been a multitude of studies on the psychological contract between employee and organization over the last 20 years, demonstrating the explanatory power of psychological

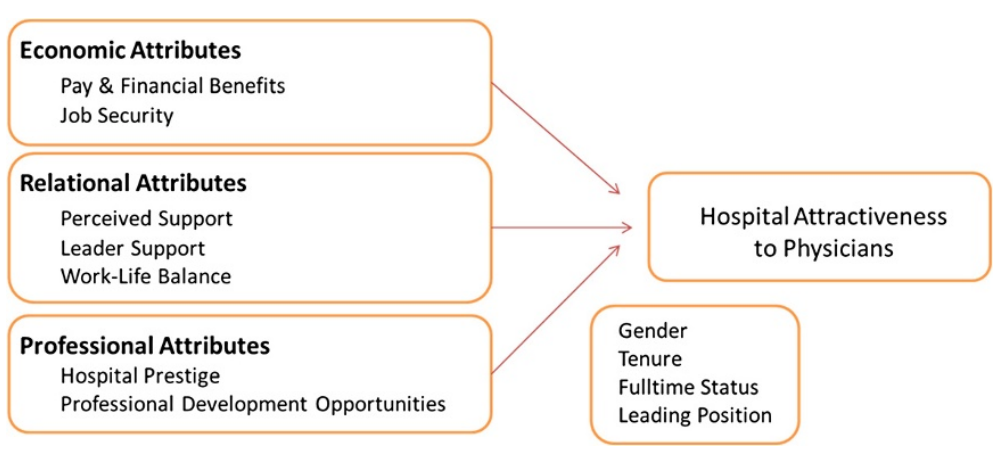

Figure 1 Conceptual framework. 
contract fulfilment and/or breach to a variety of workrelated attitudinal and behavioural outcomes [22].

Applied to the HPR, the theoretical concept of the psychological contract enables us to study physicians' perceptions of specific hospital attributes (the content of the psychological contract) which shape the organizational image. Furthermore we determine to what extent these perceptions (the evaluation of the fulfillment of the contents of the psychological contract) predict organizational attractiveness.

Moreover, it has been shown that physicians do not have exactly the same objectives or motivations as the organization and do not necessarily act in the best interest of the organization [11]. Organizational attractiveness provides a way of accounting for this agency problem associated with employment relationships [23]. In support of this assumption, previous research demonstrated that physicians' perceptions of their healthcare organization's image were positively associated with their tendency to engage in cooperative and organizational citizenship behaviors [24]. In this respect, psychological contracts have an important impact on hospitals' ability to attract, retain and motivate scarce physicians.

Clearly, many aspects determine physician's perceptions of hospitals attributes thereby shaping the organizational image. One aspect of an organization's offering will be the financial conditions. Prior research focusing on HPRs has paid a lot of attention to the economic arrangements between hospital and medical staff members [17], an aspect that has dominated previous research [11]. Building on these insights we included two attributes reflecting the economic relationship: physicians' perceptions of the degree to which he or she is fairly rewarded (pay and financial benefits) and job security.

Hypothesis 1: Hospital economic attributes (pay and financial benefits and job security) are positively related to the perceived attractiveness of the hospital as an employer.

While the economic approach has been widely used to increase insight into the complex issue of hospitalphysician relationships, these studies have been criticized because they assume that human motivation is primarily based on self-interest and ignore the fact that economic transactions are embedded in social relationships $[25,26]$. They fail to recognize that physicians have a more complex set of motives that underlie their behavior [27].

Besides these economic rewards, intrinsic rewards provided by hospitals will fulfill for example socio-emotional needs. As such, the employment experience is made up of a complex array of features [28]. Prior research on HPRs has made a similar distinction between the economicfinancial relationship and the relational perspective (non- economic relationship) focusing on the cooperative nature of the day-to-day working relationship [11]. Outside the context of HPRs, considerable research has been conducted on the impact of quality of exchange relationships with the organization (perceived organizational support) and leader (leader-member exchange) on a multitude of work-related attitudes and behaviors. Specifically, perceived organizational support and leadermember exchange has been related to a variety of workrelated outcomes such as affective commitment, trust and intention to leave [29] and organizational citizenship behavior [30]. Furthermore, in the past decade there has been increasing interest of organizational researchers in the concept of work-life balance. The business case for work-life balance practices relies on the ability to reduce work-life conflict among employees thereby improving employee attitudes and behaviors within the organization [31]. We build further on this insight by including these three attributes: the perceived degree to which the hospital values and listens to its employees (organizational support), the perceived degree to which the immediate leader can be relied upon and is willing to listen to job-related problems (leader support) and the degree to which the hospital offers good working hours and makes efforts to meet physicians' expectations of work-life balance (work-life balance).

Hypothesis 2: Hospital relational attributes (perceived support, leader support and work-life balance) are positively related to the perceived attractiveness of the hospital as an employer.

Finally, when considering non-economic aspects of the HPR, it has been recognized that an ideologically pluralistic work setting is present. In hospitals ideologies of professional work bump up against ideologies of the administrative organization in determining the appropriate terms of the physician employment relationship [19,32]. In other words, physicians interact with the hospital both as professional and as employee. Both roles shape HPRs and determine a set of a priori expectations about roles, rights and obligations. Two specific professional expectations were included. First, we included the degree to which the hospital is highly regarded and respected (hospital prestige). Since the organization under study has an academic status which distincts the hospital from (non-academic) general hospitals this could be an important attribute from a professional point of view. Second, the perceived opportunities for training and education (professional development opportunities) were included. More precisely, this refers to the ability of physicians to acquire and improve their professional skills and knowledge. 
Hypothesis 3: Hospital professional attributes (hospital prestige and professional development opportunities) are positively related to the perceived attractiveness of the hospital as an employer.

Overall, three dimensions (economic, professional and relational attributes) are considered. In addition, the relative importance of these individual attributes and dimensions is determined. Although the importance of an organizational image has received a lot of theoretical attention, relatively few empirical studies have examined this issue. Although research focusing on HPRs has stressed the importance of economic, administrative and professional aspects, these can be as considered isolated studies and little is known about the relative importance in shaping hospital attractiveness.

\section{Methods}

This study was conducted in a medium-sized Belgian academic hospital and concentrates on the medical staff members to study the hospital-physician relationship.

\section{Instruments}

Hospital attractiveness was measured using four items on a seven point Likert scale from 1 = strongly disagree to 7 = strongly agree, with high scores indicating high attractiveness. This instrument has demonstrated adequate levels of reliability in previous research [33]. Sample items are '[hospital name] is attractive to me as a place for employment' and 'I would recommend [hospital name] as an employer to my friends'. To measure organizational attributes, the scale from Lievens and colleagues [13] was adapted to the hospital context. By means of focus groups we determined organizational attributes potentially important to predict hospital attractiveness. Two semistructured interviews with in total sixteen participants were performed. Due to the exploratory nature of our study which concentrated on collecting and testing numerous brief suggestions this number is considered appropriate [34]. Discussion topics were based on the known antecedents of organizational attractiveness and additional antecedents conveyed by the participants. The interviews focused on what employees found important about their job and the organization. This allowed us to drop irrelevant attributes and add relevant ones that were missing. During this process, different antecedents that were identified in previous studies but were not important to the context of the physician-hospital relation were no longer considered (i.e. travel opportunities) while 'hospital prestige' was added. During the course of the interview, we increasingly encountered the same organizational characteristics, suggesting that we reached a state of data saturation. The outcomes of the interviews with the focus groups were used to construct a questionnaire. Factor analysis indicated seven factors with an eigenvalue higher than one. As a rule of thumb, items which loaded less than 0.6 on their own factor or more than 0.4 on other factors were removed from the analysis. Therefore, 2 items were omitted resulting in 15 remaining items. The scale items are outlined in Additional file 1. The seven factors correspond with the antecedents that were identified by the focus groups. All items were measured using a 7-point Likert scale.

As a first step, we began checking the internal consistencies of the scales. Internal consistency of the factors was satisfactory, with values for Cronbach's alpha ranging between 0.69 and 0.98. The instrumental factors are: pay and financial benefits, job security (economic attributes), organizational support, leader support, work-life balance (relational attributes), hospital prestige and professional development opportunities (professional attributes).

A demographic questionnaire was incorporated in the survey to obtain descriptive information. Individuals' gender, age, tenure within the organization, professional experience, work schedule (full-time versus part-time employment) and whether or not the physician has a leading position were included as covariates in our analyses to rule out potential alternative explanations for our findings. Previous research has shown that these variables are potentially important to understand organizational attractiveness [35].

\section{Statistical analysis}

Data were analyzed using The Statistical Package for Social Sciences (SPSS) version 20.0 for Windows (SPSS, Inc., Chicago, IL, USA). Descriptive statistics, correlations and reliability coefficients were generated for the analyzed variables. We ran a hierarchical regression, controlling for gender, tenure, fulltime versus part-time employment (dummy-coded) and whether or not the respondent has a leading function (dummy coded). Age and professional experience were not used as control variables due to multicollinearity between these two variables and tenure. Because the correlation between these three variables was high (the spearman correlation coefficients were 0.808 and 0.845 respectively), little impact should be expected from omitting both variables.

\section{Post hoc power test}

The data were analyzed by hierarchical multiple linear regression. Because of our limited sample size, a posthoc sample calculation was performed. Based on a statistical significance level of 0.05 , a power of 0.80 and a medium effect size of 0.20 , the test revealed that approximately 68 subjects would be needed for a regression analysis with ten independent variables and one dependent variable [36]. Thus, although our sample was 
relatively small, it had an adequate power to test the stated hypothesis.

\section{Relative importance analyses}

In addition, we examined the relative importance of the organizational attributes in determining organizational attractiveness. However, since the measures of independent variables are interrelated the regression coefficients are not interpretable as measures of relative importance vis-à-vis the others [37] and the regression coefficients were therefore supplemented with relative weights. These relative weights were computed with the analytical approach of Johnson [38]. Relative weights are defined as the proportionate contribution of each independent variable to $\mathrm{R}^{2}$, considering both its unique contribution and most importantly also the contribution when combined with other variables. For ease of interpretation we express them as percentages of the predictable variance $\left(R^{2}\right)$.

\section{Ethical considerations}

Our study was approved by the Medical Ethics Committee of the Université Catholique de Louvain. The questionnaire was distributed to all staff members together with a letter explaining the purpose of the study. Participation to the study was voluntary. Questionnaires were retrieved and processed by non-hospital members to assure anonymity.

\section{Results}

\section{Participants}

The data were collected by paper-and-pencil questionnaires. Although researchers have regularly encountered poor response rates when surveying physicians [39], of the 149 physicians, 86 returned the survey. This represented a satisfactory response rate of $57.8 \%$. This response was felt to be adequate for an exploratory study of the instrument to the HPR-setting. Sample characteristics are included in Table 1. Most participants were male (54.7\%) and were fulltime employed (76.7\%). The physicians were on average 45 years old and had more than 10 years experience in the organization (53.6\%). These figures are comparable with the characteristics of the whole medical staff $(66 \%$ are male, $88 \%$ are fulltime employed and had on average 10.7 years experience in the organization).

\section{Descriptive statistics}

Table 2 presents the means, standard deviations and correlations of these variables in this study. Internal consistencies are on the diagonal. All variables were significantly related to hospital attractiveness. This is not surprising in light of our qualitative pre-study to identify relevant variables. To test our hypotheses we conducted a multiple regression analysis.
Table 1 Participants' demographics

\begin{tabular}{|c|c|c|}
\hline & $\mathrm{N}$ & $\%$ \\
\hline \multicolumn{3}{|l|}{ Gender } \\
\hline Male & 47 & 54.7 \\
\hline Female & 39 & 45.3 \\
\hline \multicolumn{3}{|l|}{ Age } \\
\hline Ranges from 26 to 64 & Mean $=44.88$ & $S D=10.32$ \\
\hline \multicolumn{3}{|l|}{ Organizational tenure } \\
\hline$<5$ years & 25 & 29.8 \\
\hline 5 to 10 years experience & 14 & 16.6 \\
\hline 10 to 20 years experience & 26 & 31.0 \\
\hline$>20$ years experience & 19 & 22.6 \\
\hline Fulltime employment & 66 & 76.7 \\
\hline Leading position & 24 & 27.9 \\
\hline
\end{tabular}

\section{Impact of hospital attributes}

Based on hierarchical linear regression analysis, the set of hospital attributes was found to have a significant and positive effect on organizational attractiveness. The attributes jointly explained a significant amount of variance (Adjusted $\mathrm{R}^{2}=0.793 ; \mathrm{P}<0.001$ ). This high amount can be explained by the holistic view we applied to the HPR and the thorough build-up of our model by means of a literature review and focus groups. Table 3 provides an overview.

In the first step, the control variables were added. Having a leading position within the hospital $(\mathrm{P}=0.002 ; \beta=-0.248)$ and tenure $(P=0.046 ; \beta=0.148)$ were significant predictors of hospital attractiveness. The explained variance was however limited (for leadership $0.8 \%$ and tenure 1.6\%). Gender $(P=0.900 ; \beta=-0.009)$ and full-time employment $(P=0.477$ $\beta=-0.048)$ were no statistically significant predictors.

In the second step, the organizational attributes were added. Our organizational attributes explained $76.0 \%$ of the variance. Professional attributes were identified as the strongest predictors (35.3\%); professional development opportunities $(P=0.003, \beta=0.280)$ explained $18.8 \%$ of the variance and hospital prestige $(\mathrm{P}<0.001, \beta=0.291)$ explained $16.5 \%$. This confirmed the argument noted by the participants of the exploratory focus groups which led to the inclusion of prestige as an additional hospital characteristic. Besides professional aspects of the HPR, relational attributes were found to be important (29.7\%). Organizational support $(P=0.001 ; \beta=0.337)$ explained $17.2 \%$ variance; leader support $(P=0.033 ; \beta=0.170)$ explained 9.3\% variance and work-life balance $(\mathrm{P}=0.156$; $\beta=-0.125) 3.3 \%$. Third, economic aspects accounted for $10.9 \%$ of variance. Pay and financial benefits $(P=0.004$; $\beta=0.203)$ explained $7.4 \%$ and job security $3.6 \%(P=0.642$; $\beta=0.033)$. The economic attributes are less important 
Table 2 Means, standard deviations and correlations of study variables

\begin{tabular}{|c|c|c|c|c|c|c|c|c|c|c|c|c|c|c|}
\hline & Mean & SD & 1. & 2. & 3. & 4. & 5. & 6. & 7. & 8. & 9. & 10. & 11. & 12. \\
\hline \multicolumn{15}{|l|}{ Personal characteristics } \\
\hline 1. Gender & 0.55 & 0.50 & - & & & & & & & & & & & \\
\hline 2. Tenure & 44.88 & 10.32 & $0.291^{* *}$ & - & & & & & & & & & & \\
\hline 3. Employment status & 12.99 & 9.67 & $0.370^{* *}$ & 0.200 & - & & & & & & & & & \\
\hline 4. Leading position & 0.78 & 0.42 & 0.191 & $0.391^{* *}$ & 0.197 & - & & & & & & & & \\
\hline \multicolumn{15}{|l|}{ Hospital characteristics } \\
\hline \multicolumn{15}{|l|}{ Economic attributes } \\
\hline 5. Pay and financial benefits & 4.09 & 1.41 & 0.003 & 0.073 & -0.09 & -0.002 & 0.945 & & & & & & & \\
\hline 6. Job security & 5.21 & 1.29 & -0.012 & 0.066 & 0.091 & -0.118 & 0.14 & 0.703 & & & & & & \\
\hline \multicolumn{15}{|l|}{ Relational attributes } \\
\hline 7. Organizational support & 5.35 & 1.11 & -0.063 & 0.05 & -0.057 & $0.269^{*}$ & $0.371^{* *}$ & 0.165 & 0.903 & & & & & \\
\hline 8. Leader support & 3.15 & 1.60 & -0.126 & $-0.272^{*}$ & $-0.238^{*}$ & -0.19 & 0.194 & $0.286^{* *}$ & $0.294^{* *}$ & 0.981 & & & & \\
\hline 9. Work-life balance & 4.86 & 1.72 & -0.174 & $-0.298^{* *}$ & $-0.263^{*}$ & $-0.279^{*}$ & $0.407^{* *}$ & 0.195 & $0.452^{* *}$ & $0.426^{* *}$ & 0.793 & & & \\
\hline \multicolumn{15}{|l|}{ Professional bttributes } \\
\hline 10. Hospital prestige & 3.57 & 1.46 & 0.206 & $-0,066$ & 0.135 & 0.033 & 0.184 & $0.316^{* *}$ & $0.455^{* *}$ & $0.237^{*}$ & $0.259^{*}$ & 0.689 & & \\
\hline $\begin{array}{l}\text { 11. Professional } \\
\text { development } \\
\text { opportunities }\end{array}$ & 5.11 & 1.19 & -0.115 & -0.115 & -0.108 & 0.05 & $0.216^{*}$ & $0.327^{* *}$ & $0.547^{* *}$ & $0.528^{* *}$ & $0.418^{* *}$ & $0.444^{* *}$ & 0.702 & \\
\hline \multicolumn{15}{|l|}{ Dependent variable } \\
\hline 12. Hospital attractiveness & 5.29 & 1.08 & 0.037 & 0.053 & -0.04 & 0.015 & $0.408^{* *}$ & $0.300^{* *}$ & $0.606^{* *}$ & $0.529^{* *}$ & $0.389^{* *}$ & $0.588^{* *}$ & $0.702^{* *}$ & 0.918 \\
\hline
\end{tabular}

\section{Table 3 Regression analysis}

\begin{tabular}{|c|c|c|c|c|}
\hline & Relative weights & Relative weights as $\%$ of $\mathrm{R}^{2}$ & Relative weights & Relative weights as $\%$ of $\mathrm{R}^{2}$ \\
\hline Personal characteristics & & & $3.3 \%$ & $4.1 \%$ \\
\hline Gender & $0.6 \%$ & $0.75 \%$ & & \\
\hline Tenure & $0.8 \%$ & $1.06 \%$ & & \\
\hline Fulltime employment & $0.2 \%$ & $0.31 \%$ & & \\
\hline Leading & $1.6 \%$ & $2.02 \%$ & & \\
\hline Organizational attributes & & & $76.0 \%$ & $95.9 \%$ \\
\hline Economic attributes & & & $10.9 \%$ & \\
\hline Pay and financial benefits & $7.4 \%$ & $9.28 \%$ & & \\
\hline Job security & $3.6 \%$ & $4.51 \%$ & & \\
\hline Relational attributes & & & $29.7 \%$ & \\
\hline Organizational support & $17.2 \%$ & $21.66 \%$ & & \\
\hline Leader support & $9.3 \%$ & $11.67 \%$ & & \\
\hline Work-life balance & $3.3 \%$ & $4.14 \%$ & & \\
\hline Professional attributes & & & $35.3 \%$ & \\
\hline Hospital prestige & $16.5 \%$ & $20.84 \%$ & & \\
\hline Professional development opportunities & $18.8 \%$ & $23.75 \%$ & & \\
\hline$R^{2}$ & 0.793 & & & \\
\hline
\end{tabular}


than the non-economic attributes (relational and professional attributes) mentioned above. Table 3 provides a full overview. The first two columns present the relative weights and the percentage of predictable variance (relative weights as a percentage of $R^{2}$ ). The last two columns provide an overview of the aggregated relative weights and percentage of predictable variance of the personal characteristics, economic, relational and professional attributes.

\section{Discussion}

A key aim of this study was to address the lack of research on the relative importance of different hospital attributes that determine hospital attractiveness to physicians. In light of the physician shortage [4], the physician fled to self-owned ambulatory facilities [2] and increased competition between general hospitals [12], the insights developed by this study are of major importance.

First, our findings demonstrate the importance of professional attributes. Both hospital prestige and opportunities for physicians to develop themselves professionally were major predictors of hospital attractiveness. These findings confirm the results of previous research [19,32] that showed that the psychological contract of physicians also consists of a professional dimension. Therefore it is clear that the broader institutional context of the HPR cannot be neglected. However, the professional aspects of the HPR remain largely an unexplored terrain. While we increase insight by exploring the importance physicians' perceptions of hospital prestige and professional development opportunities future research needs to clarify this issue further.

Second, relational attributes of hospitals were also identified as an important predictor of hospital attractiveness. This finding is supported by the rich theoretical and empirical evidence rooted within social exchange. At the core of this approach is the norm of reciprocity which is described as the social expectation that people respond positive to positive actions [40]. More precisely, perceived organizational and leader support have been identified as strong predictors of a wide variety of organizationally desired work attitudes and behaviour (e.g. job satisfaction, organizational trust, organizational citizenship behaviour) [30,41]. We contribute to the body of knowledge by demonstrating the significance of both organizational and leader support to organizational attractiveness. Furthermore, we showed that work-life balance did not predict hospital attractiveness. This is surprising since the business case for work-life balance practices relies on the ability to reduce work-life conflict thereby potentially improving employee attitudes and behaviors within the organization [31]. However this result could be interpreted in light of the importance of professional attributes mentioned above. Professional development and prestige contrasts to a certain extent the desire to preserve leisure and family time. However, this needs further clarification. Moreover since healthcare workers experience frequently high levels of work-related stress and burn-out [42] accentuating the importance of healthy well-being at work we argue that the importance of work-life balance to professionals is an interesting direction for future research.

Third, our findings confirm the statement that the economic relationship between hospital and physician is only of limited importance. This contrasts the focus of previous research which has concentrated predominately on financial alignment issues between both parties [17]. Moreover, these studies assume that human motivation is primarily based on self-interest and ignore the fact that economic transactions are embedded in social relationships. Our finding highlights the fact that physicians, as professionals, have a more complex set of motives that underlie their behavior. This confirms Herzberg's [43] view on financial conditions which in the two factor theory are identified as a hygiene factor which does not give positive satisfaction, though dissatisfaction results from its absence. Furthermore, hospitals are practicing in an increasingly competitive environment characterized by a physician shortage in which financial conditions cannot be neglected. However, in general we advise hospital administrators and policy makers not to reduce the HPR to a financial or economic relationship and apply a diverse strategy in which besides economic ties, also relational and professional aspects are considered.

However, in light of this finding it is important to note that this study focused on employed physicians practicing at a university hospital and it could be that this issue is of greater importance to a setting in which physicians are self-employed. This issue warrants further research.

Finally, our quantitative study did not identify job security as an important predictor. Bearing in mind that the physician labor market is characterized by a chronic physician shortage this finding is not that surprising. However, this confirms and highlights the importance of hospital management to increase hospital attractiveness in order to retain scarce physicians in a highly competitive labor market.

\section{Limitations}

The cross-sectional nature of our study precludes strong claims of causality. A longitudinal study to examine changes over time would be valuable. Furthermore, our study comprises a small sample size and includes only one Belgian academic hospital. It would be insightful to replicate this study using a larger representative sample of hospitals. In addition, it would be valuable to perform an international study that also considers differences between different types of health care systems and countries. However, the 
theoretical support for our results and findings of previous research with potential applicants and employees outside the healthcare setting is encouraging and suggests that further research is warranted. More specifically, since operational linkages with the hospital (i.e. the use of the operating theatre and supporting personnel) and remuneration (i.e. medical fees) differs between medical specialties, a study focusing on the potential differences of attributes between different types of physicians (e.g. pediatrics vs. orthopedics) would be interesting. Also, our study focused on a large academic hospital. It would be valuable to study differences between physicians practicing at academic hospitals and physicians practicing at general hospitals. Moreover the opportunities with respect to teaching, research and opportunities to deliver highly (sub)specialized care differ between academic and non-academic hospitals and therefore the relative importance of hospital attributes could be different. In addition, it is important to note that in Belgian academic hospitals physicians are salaried employees. This contrast with the setting of self-employed physicians. It is likely that the different economic ties shape the hospital-physician relationship to a great extent. Moreover, the difference in the relative importance of economic and the various noneconomic factors to self-employed physicians would be interesting to investigate. Studies focusing on these other settings provide valuable avenues for future research. Finally, the impact of hospital attributes and attractiveness to physicians on other important managerial outcomes such as retention of physicians, organizational attitudes (e.g. organizational commitment) and performance (e.g. organizational citizenship behavior) pose interesting possibilities for future research.

\section{Conclusions}

In this study we conceptualized hospital attractiveness to physician specialists as a package of organizational attributes. We examined the relative importance of these attributes in shaping the organizational image thereby determining organizational attractiveness to physicians practicing at that hospital. Our results show that hospital attractiveness is primarily determined by non-economic factors. Hospital attractiveness is most strongly predicted by the professional attributes (professional development opportunities and prestige). Furthermore relational attributes are important (organizational support and leader support). Work-life balance and job security did not contribute significantly. In addition, physicians indicated pay and financial benefits as an economic predictor of hospital attractiveness. However, this economic dimension of the hospital-physician relationship is less important than the non-economic characteristics contributing to an attractive work environment.

\section{Additional file}

\section{Additional file 1: Scale items for hospital attributes (7-point Likert} scale).

\section{Competing interests}

The authors declare that they have no competing interests.

\section{Authors' contributions}

All authors made substantial contributions to the conception and design, acquisition of data, or analysis and interpretation of the data. All authors were involved in drafting the manuscript and revising it for important intellectual content and gave final approval of the version to be published.

\section{Author details}

'Department of Public Health, Ghent University, De Pintelaan 185, Gent B-9000, Belgium. ²Department of Management, Innovation and Entrepreneurship, Center for Service Intelligence, Ghent University, Tweekerkenstraat 2, Gent B-9000, Belgium. ${ }^{3}$ Research Center for Human Relations, KU Leuven, Warmoesberg 26, Leuven 1B-000, Belgium. ${ }^{4}$ Faculty of Medicine and Pharmacy, Vrije Universiteit Brussel, Pleinlaan 2, Brussels, Elsene B-1050, Belgium.

Received: 20 September 2013 Accepted: 13 May 2014 Published: 21 May 2014

\section{References}

1. Berenson RA, Bodenheimer T, Pham HH: Specialty-service lines: Salvos in the new medical arms race. Health Aff 2006, 25(5):337-343.

2. Al-Amin M, Housman M: Ambulatory surgery center and general hospital competition: entry decisions and strategic choices. Health Care Manage Rev 2012, 37(3):223-234.

3. Cooper RA, Getzen TA, Mckee HJ, Laud P: Economic and demographic trends signal an impending physician shortage. Health Aff 2002, 21(1):140-154.

4. Kirch DG, Mackenzie KH, Dill MJ: Physician workforce projections in an Era of health care reform. Annu Rev Med 2012, 63:435-445.

5. Martin JJM, Gonzalez M, Garcia MDC: Review of the literature on the determinants of healthcare expenditure. Appl Econ 2011, 43(1):19-46.

6. von Knorring M, de Rijk A, Alexanderson K: Managers' perceptions of the manager role in relation to physicians: a qualitative interview study of the top managers in Swedish healthcare. BMC Health Serv Res 2010, 10:271.

7. Kaissi A: Manager-physician relationships: an organizational theory perspective. Health Care Manag 2005, 24(2):165-176.

8. Cortese D, Smoldt R: Taking steps toward integration. Health Aff 2007, 26(1):68-71.

9. Goes JB, Zhan C: The effects of hospital-physician integration strategies on hospital financial performance. Health Serv Res 1995, 30(4):507-530.

10. Safavi K: Aligning financial incentives. J Healthc Manage 2006, 51(3):146-151.

11. Trybou J, Gemmel P, Annemans L: The ties that bind: an integrative framework of physician-hospital alignment. BMC Health Serv Res 2011, $11: 36$

12. Chapman DS, Uggerslev KL, Carroll SA, Piasentin KA, Jones DA: Applicant attraction to organizations and job choice: A meta-analytic review of the correlates of recruiting outcomes. J App/ Psychol 2005, 90(5):928-944.

13. Lievens F, Van Hoye G, Schreurs B: Examining the relationship between employer knowledge dimensions and organizational attractiveness: an application in a military context. J Occup Organ Psych 2005, 78(4):553-572.

14. Mascia D, Di Vincenzo F: Understanding hospital performance: the role of network ties and patterns of competition. Health Care Manage Rev 2011, 36(4):327-337.

15. Frandsen S: Organizational image, identification, and cynical distance: prestigious professionals in a low-prestige organization. Manage Commun Q 2012, 26(3):351-376.

16. Hekman DR, Bigley GA, Steensma HK, Hereford JF: Combined effects of organizational and professional identification on the reciprocity dynamic for professional employees. Acad Manage J 2009, 52(3):506-526. 
17. Burns LR, Muller RW: Hospital-physician collaboration: landscape of economic integration and impact on clinical integration. Milbank Q 2008, 86(3):375-434.

18. Trybou J, Gemmel P, Annemans L: How to govern physician-hospital exchanges: contractual and relational issues in Belgian hospitals. $J$ Health Serv Res Policy 2014, doi:10.1177/1355819613518765.

19. Bunderson J: How work ideologies shape the psychological contracts of professional employees: doctors' responses to perceived breach. J Organ Behav 2001, 22(7):717-741.

20. Swystun J: The Brand Glossary. New York: Palgrave Macmillan; 2007.

21. Rousseau DM: Psychological and implied contracts in organization. Empl \%ities Rights J 1989, 2(2):121-139.

22. Coyle-Shapiro JAM, Conway N: Exchange relationships: examining psychological contracts and perceived organizational support. J Appl Psychol 2005, 90(4):774-781.

23. Albert S, Ashforth BE, Dutton JE: Organizational identity and identification: charting new waters and building new bridges. Acad Manage Rev 2000, 25(1):13-24a. 14

24. Dukerich JM, Golden BR, Shortell SM: Beauty is in the eye of the beholder: the impact of organizational identification identity and image on the cooperative behaviors of physicians. Admini Sci Quart 2002, 47(3):507-553.

25. Ghoshal S, Moran P: Bad for practice: a critique of the transaction cost theory. Acad Manage Rev 1996, 21(1):13-47.

26. Granovetter M: Economic action and social structure: the problem of embeddedness. Am J Sociol 1985, 91(3):481-510.

27. Kunz AH, Pfaff D: Agency theory, performance evaluation, and the hypothetical construct of intrinsic motivation. Account Org Soc 2002, 27(3):275-295.

28. Edwards MR: An integrative review of employer branding and OB theory. Pers Rev 2009, 39(1):5-23.

29. Dulac T, Coyle-Shapiro JAM, Henderson DJ, Wayne SJ: Not all responses to breach are the same: the interconnection of social exchange and psychological contract processes in organizations. Acad Manage J 2008, 51(6):1079-1098

30. Trybou J, Gemmel P, Pauwels Y, Henninck C, Clays E: The impact of organizational support and leader-member exchange on the work-related behaviour of nursing professionals: the moderating effect of professional and organizational identification. J Adv Nurs 2014, 70(2):373-382.

31. Beauregard TA: Making the link between work-life balance practices and organizational performance. Hum Resour Manage R 2009, 19(1):9-22.

32. Bunderson JS, Lofstrom SM, Van De Ven AH: Conceptualizing and measuring professional and administrative models of organizing. Organ Res Methods 2000, 3(4):366-391

33. Highhouse $\mathrm{S}$, Lievens F, Sinar EF: Measuring attraction to organizations. Edu Psychol Meas 2003, 63(6):986-1001.

34. Morgan DL: The Focus Group Kit. Planning Focus Groups. California: Thoasand Oaks: Sage Publications; 1998

35. Lievens F, Highhouse S: The relation of instrumental and symbolic attributes to a company's attractiveness as an employer. Pers Psychol 2003, 56(1):75-102

36. Faul F, Erdfelder E, Buchner A, Lang AG: Statistical power analyses using G*Power 3.1: tests for correlation and regression analyses. Behav Res Methods 2009, 41(4):1149-1160.

37. Darlington RB: Multiple regression in psychological research and practice. Psychol Bull 1968, 69(3):161-182.

38. Johnson JW: A heuristic method for estimating the relative weight of predictor variables in multiple regression. Multivar Behav Res 2000, 35 (1):1-19.

39. Templeton L, Deehan A, Taylor C, Drummond C, Strang J: Surveying general practitioners: does a low response rate matter? Brit J Gen Practice 1997, 47(415):91-94.

40. Coyle-Shapiro JAM, Shore L, Taylor M, Tetrick L: The Employment Relationship: Examining Psychological and Contextual Perspectives. Oxford: Oxford University Express; 2010.
41. Trybou J, De Pourcq K, Paeshuyse M, Gemmel P: The importance of social exchange to nurses and nursing assistants: impact on retention factors. J Nurs Manage 2013, doi:10.1111/jonm.12039.

42. Ramirez AJ, Graham J, Richards MA, Cull A, Gregory WM: Mental health of hospital consultants: the effect of stress and satisfaction at work. Lancet 1996, 16(347):724-728.

43. Herzberg F: Work and the Nature of Man. Cleveland: World Publishing; 1966.

doi:10.1186/1472-6963-14-232

Cite this article as: Trybou et al.: Hospital-physician relations: the relative importance of economic, relational and professional attributes to organizational attractiveness. BMC Health Services Research 2014 14:232

\section{Submit your next manuscript to BioMed Central and take full advantage of:}

- Convenient online submission

- Thorough peer review

- No space constraints or color figure charges

- Immediate publication on acceptance

- Inclusion in PubMed, CAS, Scopus and Google Scholar

- Research which is freely available for redistribution

Submit your manuscript at www.biomedcentral.com/submit
C Biomed Central 